Review began 08/31/2021 Review ended 09/10/2021 Published 09/17/2021

๑) Copyright 2021

Tiewsoh et al. This is an open access article distributed under the terms of the Creative Commons Attribution License CCBY 4.0., which permits unrestricted use, distribution, and reproduction in any medium, provided the original author and source are credited.

\section{Methotrexate-Induced Septicemia With Severe Pancytopenia and Diffuse Cutaneous Ulcerative Lesions}

\author{
Iadarilang Tiewsoh ${ }^{1}$, Biswajit Dey ${ }^{2}$, Mary Chhangte ${ }^{3}$, Monaliza Lyngdoh ${ }^{4}$, Varsha Sathees ${ }^{4}$ \\ 1. General Medicine, North Eastern Indira Gandhi Regional Institute of Health and Medical Sciences, Shillong, IND 2. \\ Pathology, North Eastern Indira Gandhi Regional Institute of Health and Medical Sciences, Shillong, IND 3. \\ Dermatology, North Eastern Indira Gandhi Regional Institute of Health and Medical Sciences, Shillong, IND 4. Internal \\ Medicine, North Eastern Indira Gandhi Regional Institute of Health and Medical Sciences, Shillong, IND
}

Corresponding author: Iadarilang Tiewsoh, iadarilang@yahoo.com

\begin{abstract}
Methotrexate, a folate antimetabolite and one of the first few anti-neoplastic drugs, is now a commonly used drug in the treatment of many inflammatory disorders ranging from diseases like rheumatoid arthritis to psoriasis. The life-threatening toxicity of methotrexate in inflammatory diseases is not commonly encountered. Here we report a case of life-threatening multiorgan failure from methotrexate toxicity, which was given for skin lesions suspected to be psoriasis.
\end{abstract}

Categories: Internal Medicine, Infectious Disease, Rheumatology

Keywords: psoriasis, septicemia, ulcerative lesions, pancytopenia, toxicity, methotrexate

\section{Introduction}

Methotrexate is a folate antimetabolite and the first few anti-neoplastic drugs that were administered for diseases like lymphoma and leukemia in high doses [1]. However, with the evolving evidence of its antiinflammatory and immunomodulation properties, it has become one of the drugs of choice in many diseases like rheumatoid arthritis, small vessel vasculitis, and psoriasis [2-4]. The toxicity of methotrexate has been reported with both high and low doses and some risk factors are known to contribute to the toxicity [5-7].

Here we report a case of methotrexate toxicity with life-threatening multiorgan failure given to a patient with suspected cutaneous psoriasis.

\section{Case Presentation}

A middle-aged male of 46 years old, who is a chronic alcoholic, presented to the emergency department with multiple blisters and hemorrhagic crusting involving both upper and lower limbs and trunk for the last two months. The lesions started on the upper limbs as blisters and erosions following which the patient consulted a dermatologist (Figure 1). With a clinical suspicion of psoriasis, the patient was prescribed oral methotrexate weekly and topical steroids by a private practitioner. However after two weeks of the medication, the lesions increased resulting in multiple necrotic ulcers and hyperpigmented papules, macules distributed on the chest, the lower limbs and upper limbs bilaterally and erosions and necrotic ulcers on the back, some covered with crusts (Figure 2). This was followed by high-grade fever and difficulty in breathing. There was also a history of bleeding from the gums, mouth, and nasal cavity five days prior to admission. The patient went into a stage of altered sensorium and was rushed to our center for further management. On examination, the patient had mucositis of the buccal mucosa, active bleeding from the gums and nasal cavity. Examination of the skin lesions revealed multiple blisters and erythematous to hyperpigmented, scaly, and crusts on the neck, trunk, and limbs. There were multiple ulcers over these lesions with some of them were showing hemorrhagic crusts (Figure 3). 


\section{Cureus}

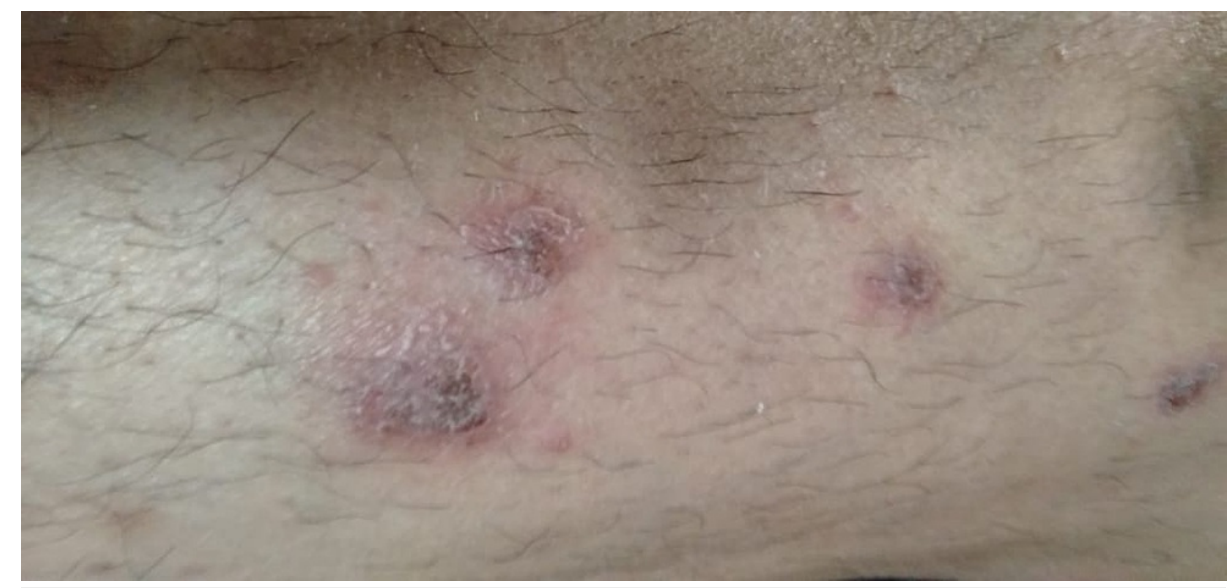

FIGURE 1: Initial lesion showing a blister on the upper part of the forearm and few vesicles with surrounding erythema and oedema on the lower part of the forearm.

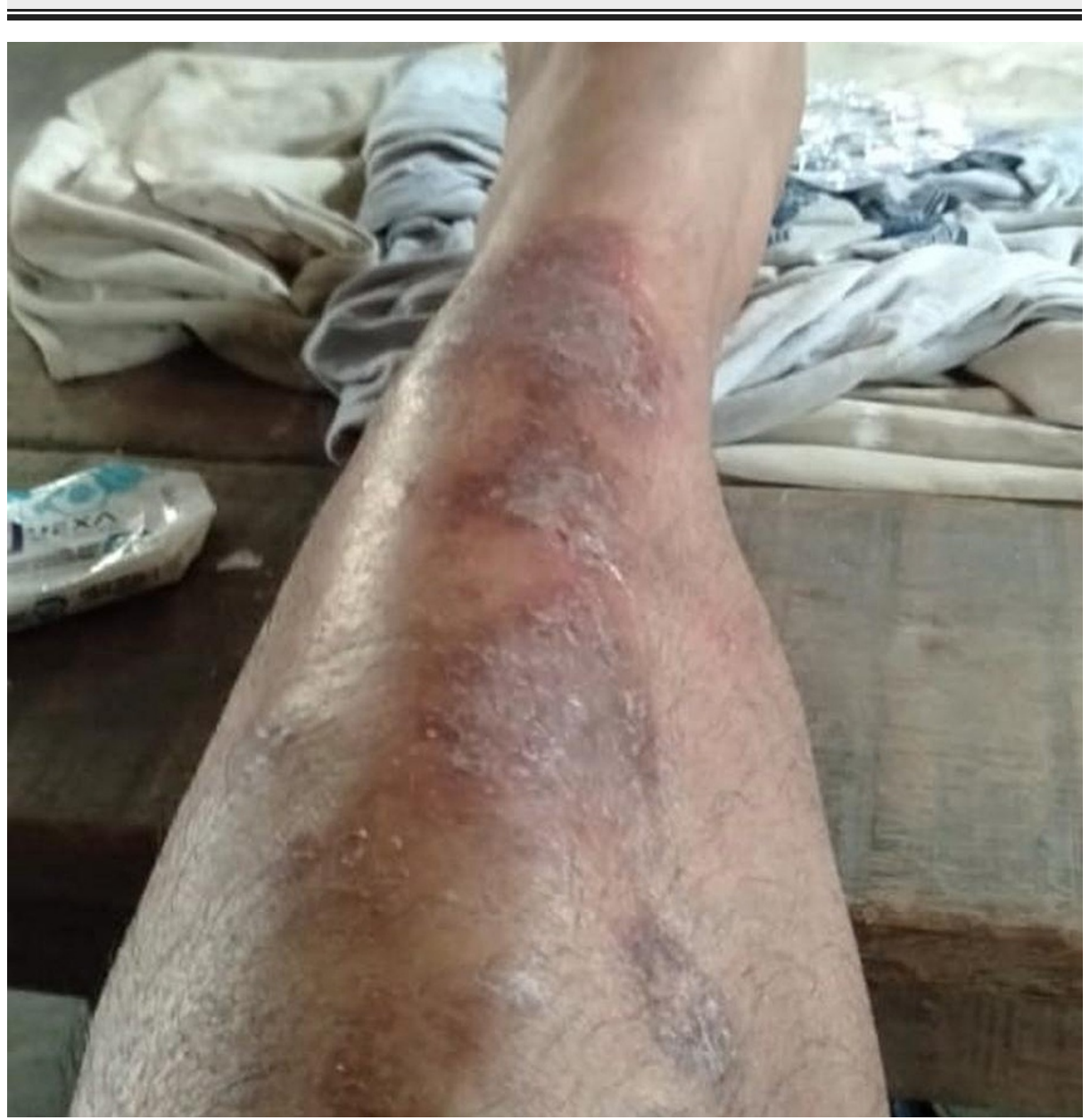

FIGURE 2: Few erythematous macules and scaly plaques with oedema on the lower limb. 


\section{Cureus}

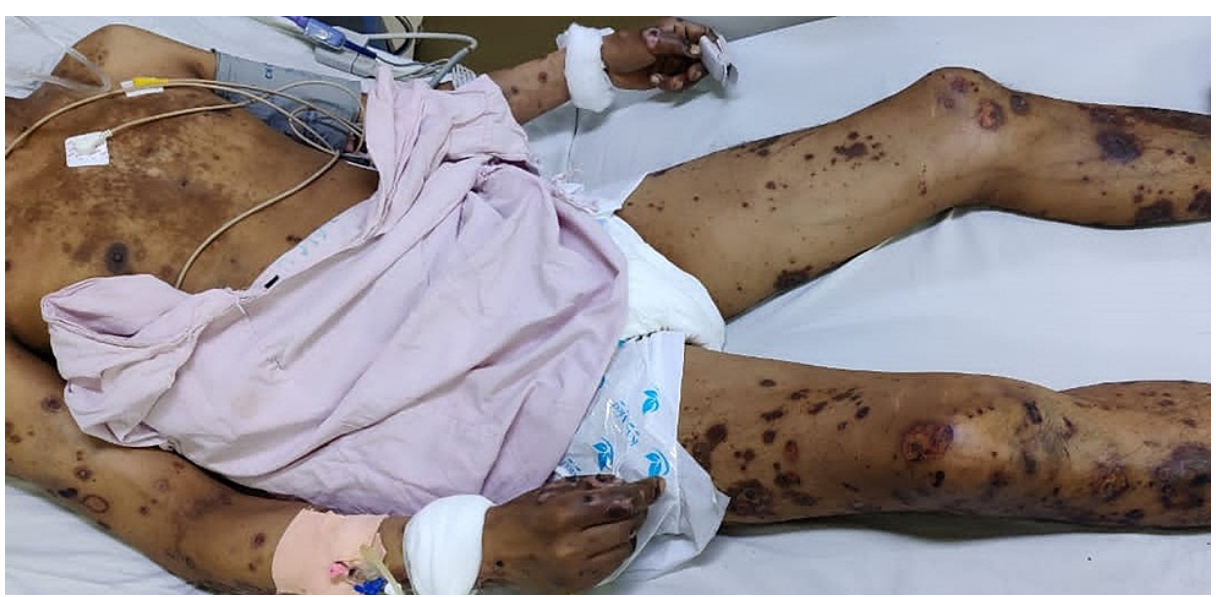

FIGURE 3: Multiple necrotic ulcers and hyperpigmented papules and macules distributed on the chest, the lower limbs and upper limbs bilaterally. Multiple erosions and necrotic ulcers on the back, some covered with crusts. Some of the lesions are healing with hyperpigmentation.

His baseline saturation was $60 \%$ at room air and $91 \%$ with high flow oxygen therapy. Systemic examination revealed basal crepitations on respiratory examination and Glasgow Coma score of 5/15 with no focal neurological deficits. A CT brain was down to rule out any intracranial hemorrhage which did not show any obvious abnormality. Laboratory investigations revealed severe pancytopenia with hemoglobin of $6 \mathrm{gm} \%$, total leucocyte count (TLC) of 300/cumm, platelets of 5000/cumm, and a reticulocyte count of $0.08 \%$. Peripheral blood smear showed macrocytic anemia with target cells, leukocytopenia with lymphocytosis, and severe thrombocytopenia. Biochemical parameter like serum lactate dehydrogenase (LDH) was raised (475 $\mathrm{IU} / \mathrm{L})$ and serum procalcitonin was elevated $(25.24 \mathrm{ng} / \mathrm{mL})$. His serum creatinine was $2.5 \mathrm{mg} / \mathrm{dL}$ and serum urea was $150 \mathrm{mg} / \mathrm{dL}$. Bone marrow study revealed hypocellular marrow with marked suppression of erythroid, myeloid, and megakaryocytic cell lineages favoring myelosuppression. Residual erythroid and myeloid cell lineages also showed megaloblastic changes (Figure 4). His bone marrow culture and blood culture had significant growth of methicillin-resistant Staphylococcus aureus (MRSA) which was sensitive to vancomycin. His chest X-ray was suggestive of a right lower lobe consolidation (Figure 5). His skin biopsy taken from an intact lesion on the medial aspect of the left foot showed features of psoriasis (Figure 6). With the background history of worsening symptoms after the intake of methotrexate, the multiorgan dysfunction was suspected to be due to methotrexate toxicity, however, serum methotrexate estimation could not be carried out. All the investigations are tabulated in Table 1 and Table 2 . Since low doses of methotrexate are unlikely to cause severe life-threatening complications a detailed history of the doses taken by the patient was obtained and it was found that the patient had consumed methotrexate daily at the dose of $10 \mathrm{mg}$ for two weeks which was then followed by the increase of the cutaneous lesions and other complications. Based on the above clinical and laboratory findings with no other contributing factors, a diagnosis of methotrexate toxicity was made. Naranjo Algorithm-Adverse Drug Reaction Probability scale was 1 to 4 . 


\section{Cureus}

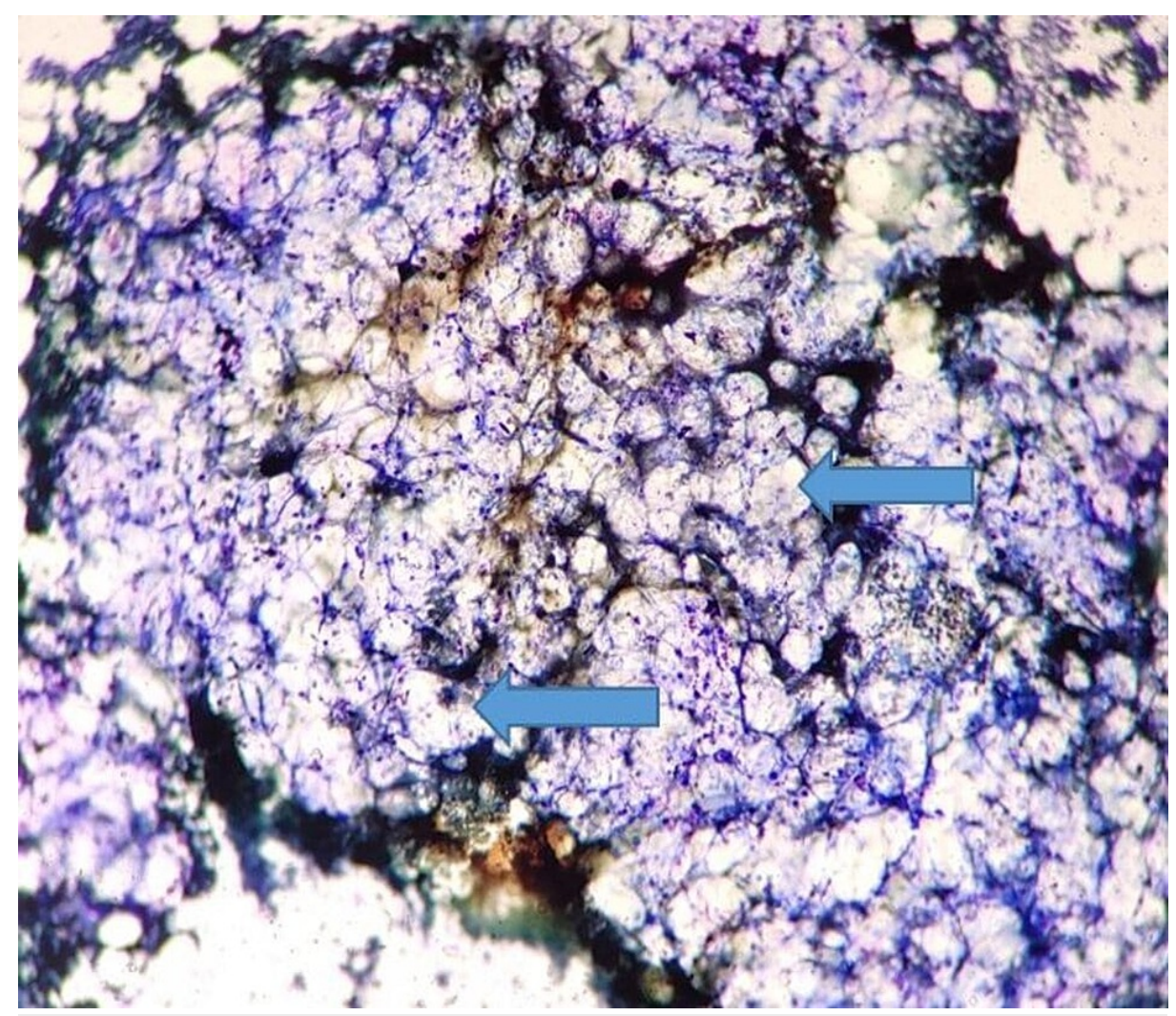

FIGURE 4: Bone marrow aspirate showing hypocellular particle with fat (arrows) replacing marrow particles (Leishman, 40x). 


\section{Cureus}

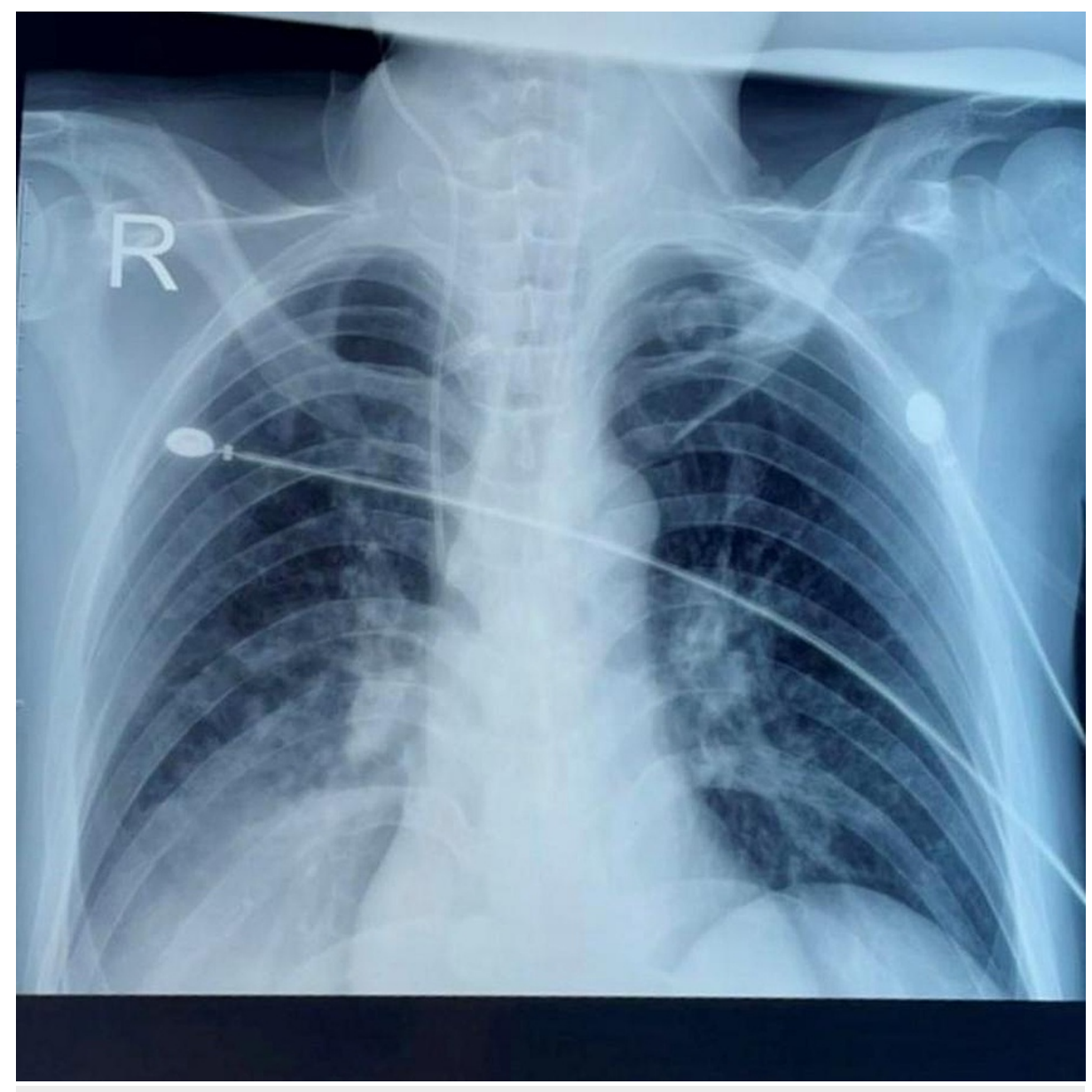

FIGURE 5: Chest X-ray showing right lower zone consolidation 


\section{Cureus}

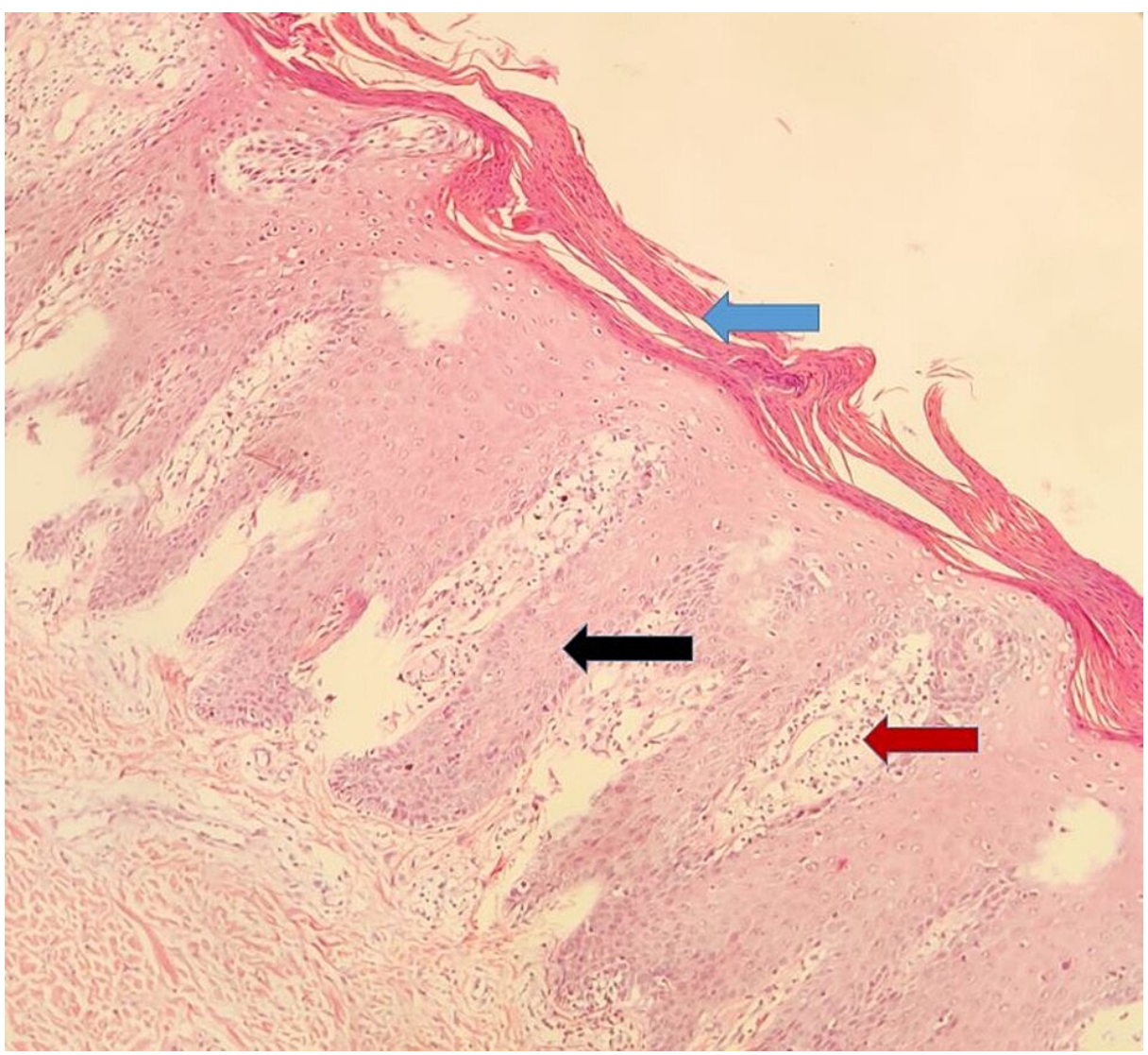

FIGURE 6: Skin biopsy showing parakeratosis of stratum corneum (blue arrow), psoriasiform hyperplasia (black arrow), and dilated capillaries in dermal papillae (red arrow) with suprapapillary thinning (H \& E, 40x). 


\section{Cureus}

\begin{tabular}{|c|c|c|c|c|}
\hline & $1^{\text {st }}$ day of admission & $\begin{array}{l}5^{\text {th }} \text { day of } \\
\text { admission }\end{array}$ & $\begin{array}{l}10^{\text {th }} \text { day of } \\
\text { admission }\end{array}$ & $\begin{array}{l}\text { On } \\
\text { discharge }\end{array}$ \\
\hline $\mathrm{Hb}(\mathrm{gm} \%)$ & 6.2 & 4.7 & 9.1 & 9.2 \\
\hline TLC (per cumm) & 300 & 2300 & 4900 & $5.7 \times 10^{3}$ \\
\hline DLC (N/L/M/E) & $38 / 50 / 06 / 06$ & 70/24/05/01 & 73/18/08/01 & $70 / 23 / 04 / 03$ \\
\hline Platelets (per cumm) & 5000 & 23,000 & 30,000 & 250,000 \\
\hline Peripheral blood smear & $\begin{array}{l}\text { Macrocytic anemia with target cells, leucocytopenia, } \\
\text { lymphocytosis and severe thrombocytopenia }\end{array}$ & & & \\
\hline ESR at the end of $1^{\text {st }}$ hour & 66 & & & \\
\hline Reticulocytes & 0.08 & & & \\
\hline Prothrombin time (sec) & 16.3 & & & \\
\hline $\begin{array}{l}\text { Activated partial } \\
\text { thromboplastin time (aPTT) } \\
\text { (sec) }\end{array}$ & 40.8 & & & \\
\hline Fibrinogen levels (mg/dl) & 267 & & & \\
\hline D-Dimer (ng/dL) & $<250$ & & & \\
\hline $\begin{array}{l}\text { International normalized ratio } \\
(\mathrm{sec})\end{array}$ & 1.41 & & & \\
\hline Urea (mg/dL) & 84 & 150 & 63 & 13 \\
\hline Creatinine (mg/dl) & 2.5 & 2.3 & 1.3 & 0.9 \\
\hline Sodium (mmol/dL) & 154.6 & 168.9 & 155.1 & 137 \\
\hline Potassium (mmol/dL) & 3.79 & 3.69 & 4.59 & 3.66 \\
\hline Chloride (mmol/dL) & 123.2 & 125.9 & 117.8 & 102 \\
\hline Total bilirubin (mg/dL) & 2.5 & 1.0 & 1.5 & 0.7 \\
\hline Direct bilirubin (mg/dL) & 1.4 & 0.4 & 0.7 & 0.2 \\
\hline AST (U/L) & 59 & 35 & 43 & 19 \\
\hline $\mathrm{ALT}(\mathrm{U} / \mathrm{L})$ & 34 & 15 & 16 & 13 \\
\hline $\operatorname{ALP}(\mathrm{U} / \mathrm{L})$ & 98 & 102 & 162 & 141 \\
\hline Total protein (g/dL) & 5.3 & 5.2 & 6.5 & 6.5 \\
\hline Albumin (g/dL) & 2.4 & 2.2 & 2.1 & 3.4 \\
\hline LDH (IU/L) & & 475 & & \\
\hline Procalcitonin $(\mathrm{ng} / \mathrm{mL})$ & & 25.24 & 5.04 & 1 \\
\hline
\end{tabular}

\section{TABLE 1: Haemotological and biochemical reports}

TLC: Total leucocyte count; DLC: Differential leukocyte count; ESR: Erythrocyte sediment rate; AST: Aspartate aminotransferase; ALT: Alanine transaminase; ALP: Alkaline phosphatase. 


\section{Cureus}

Bone marrow study Hypocellular marrow with marked suppression of erythroid, myeloid, and megakaryocytic cell lineages favoring myelosuppression. Residual erythroid and myeloid cell lineages also showed megaloblastic changes.

Bone marrow culture Staphylococcus aureus (methicillin-resistant)

Skin biopsy from the medial aspect of left foot

Psoriasiform hyperplasia with hypogranulosis and dilated capillaries with suprapapillary thinning confirming psoriasis

HBsAg / Anti-HCV

Negative

Anti-HCV

Non-reactive

VDRL

Negative

HIV

Non-reactive

ANA

Negative

RT-PCR for SARS -

CoV-2

Negative

\section{TABLE 2: Biopsy and serology reports}

HCV: Hepatitis C virus; VDRL: Venereal disease research laboratory test; ANA: Antinuclear antibody; RT-PCR: Reverse transcription-polymerase chain reaction.

The patient was intubated and ventilated on the day of admission. He was managed on the line of severe sepsis with acute kidney injury, pneumonia, and pancytopenia with supportive skincare of the ulcerated lesions. The patient was started on intravenous leucovorin calcium, $25 \mathrm{mg}$ every 6 hours on day 1, followed by $10 \mathrm{mg}$ every 6 hours on days 2 and 3 . Apart from intravenous antibiotic therapy and intravenous fluid, he received 2 units of packed red blood cells and 16 units of platelet concentrate due to upper gastrointestinal bleeding and bleeding from gums, nasal cavity, and buccal mucosa. Total parental therapy was continued for seven days. He responded to the medical treatment and on the 10th day of intensive care therapy, he was extubated and continued with supportive care. His lesions healed with the continuation of antibiotic therapy and daily dressing with povidone-iodine followed by the application of silver sulfadiazine cream. He was discharged on the 28th day of his hospital stay.

\section{Discussion}

There have been case reports of methotrexate toxicities in the form of cutaneous skin lesions, acute renal failure, pancytopenia, pneumonitis, neurotoxicity [5-13]. Here we report methotrexate toxicity following over-dosage of methotrexate by the patient resulting in life-threatening multiorgan failure with severe pancytopenia, septicemia, acute kidney injury, and diffuse cutaneous skin lesions. Toxicities like myelosuppression, pancytopenia, acute renal failure, interstitial pneumonitis, hepatitis, gastrointestinal mucositis, leukoencephalopathy are severe forms usually associated with high doses and risk factors. The severity of methotrexate toxicity can vary from mild to severe forms.

Methotrexate is a folate antagonist and inhibitor of cellular proliferation. Cells with the highest turnover such as oral mucosa, gastrointestinal tract, and bone marrow cells are the most susceptible to its effect. Thus, mucositis develops when a patient's oral epithelial cells are affected. Myelosuppression in patients with methotrexate toxicity is explained by the same mechanism [14]. As a result, pancytopenia develops, which leads to increased bleeding, easy bruising, macrocytic red blood cells, and an increased risk of infections [15].

A varied range of skin disorders has been reported with methotrexate in high to low doses. These include Stevens-Johnson syndrome (SIS), toxic epidermal necrolysis (TEN), erythema multiforme, erythroderma, papular rash, photodermatitis reaction, epidermal necrosis, and cutaneous ulceration [7-9,16].

Ulceration of the psoriatic plaques in the skin due to methotrexate toxicity is uncommon. Two patterns of skin ulceration have been described in psoriasis patients, who are treated with methotrexate. In type I ulcers, the psoriatic plaques begin to erode shortly after commencing methotrexate treatment. Type II ulcers affect uninvolved skin observed with higher dose. The pathogenic mechanism was believed to be the direct toxicity of the drug in both types. Psoriatic plaques are initially painful and red, and then they develop superficial erosions [17]. 
When methotrexate is given to patients in high or low doses all preventive measures are to be taken before administering the drug. High doses of methotrexate are administered with maintaining a good urine output, urinary alkalinization, monitoring serum creatinine, electrolytes, pharmacokinetically guided leucovorin rescue therapy and serum methotrexate estimation. Toxicities from low doses of methotrexate are stomatitis, nausea, hepatitis, cutaneous eruptions, fever, macrocytosis, and myelosuppression which can be prevented by educating and monitoring the patient from time to time along with co-administration of weekly folic acid. Immediate withdrawal of methotrexate when toxicity is encountered is an important intervention with supportive therapy. Education about the proper dosage and the related toxicity should be explained to patients before administrating the drug.

In the present case, the patient had an overdose of the drug following which he suffered a severe form of bone marrow suppression, acute renal failure, and diffuse cutaneous ulcerative lesions with septicemia. Pancytopenia could have also been contributed by folate deficiency which might have persisted before the event with the patient being a chronic alcoholic. The skin lesions of the patient could be attributed to the direct toxicity of the methotrexate therapy.

\section{Conclusions}

Methotrexate is a commonly used drug for many systemic inflammatory diseases and cutaneous lesions in clinical practice. The toxicity that our patient suffered was due to overdosage and resulted in lifethreatening complications which if not timely managed the mortality is known to be very high. Hence the toxicities that can result from methotrexate should always be considered before initiating the drug therapy. It is important for all clinicians to carry out a detailed laboratory evaluation prior to initiation of the therapy, adequate education and close monitoring during the course of therapy to avoid the adverse drug events from methotrexate.

\section{Additional Information \\ Disclosures}

Human subjects: Consent was obtained or waived by all participants in this study. Conflicts of interest: In compliance with the ICMJE uniform disclosure form, all authors declare the following: Payment/services info: All authors have declared that no financial support was received from any organization for the submitted work. Financial relationships: All authors have declared that they have no financial relationships at present or within the previous three years with any organizations that might have an interest in the submitted work. Other relationships: All authors have declared that there are no other relationships or activities that could appear to have influenced the submitted work.

\section{References}

1. Farber S, Diamond LK, Mercer RD, Sylvester RF Jr, Wolff JA: Temporary remissions in acute leukemia in children produced by folic acid antagonist, 4-aminopteroyl-glutamic acid (Aminopterin). N Engl J Med. 1948, 238:787-793. 10.1056/NEJM194806032382301

2. Weinblatt ME: Methotrexate in rheumatoid arthritis: a quarter century of development . Trans Am Clin Climatol Assoc. 2013, 124:16-25.

3. Haustein UF, Rytter M: Methotrexate in psoriasis: 26 years' experience with low-dose long-term treatment . J Eur Acad Dermatol Venereol. 2000, 14:382-388. 10.1046/j.1468-3083.2000.00058.x

4. Brion N, Paule B: Non-cancer uses of methotrexate (Article in French). Presse Med. 1996, 25:1929-1234.

5. Holmboe L, Andersen AM, Mørkrid L, Slørdal L, Hall KS: High dose methotrexate chemotherapy: pharmacokinetics, folate and toxicity in osteosarcoma patients. Br J Clin Pharmacol. 2012, 73:106-114. 10.1111/j.1365-2125.2011.04054.x

6. Mori S, Hidaka M, Kawakita T, et al.: Factors associated with myelosuppression related to low-dose methotrexate therapy for inflammatory rheumatic diseases. PLoS One. 2016, 11:e0154744. 10.1371/journal.pone.0154744

7. Yélamos $\mathrm{O}$, Català A, Vilarrasa E, Roe E, Puig L: Acute severe methotrexate toxicity in patients with psoriasis: a case series and discussion. Dermatology. 2014, 229:306-309. 10.1159/000366501

8. Chen TJ, Chung WH, Chen CB, et al.: Methotrexate-induced epidermal necrosis: a case series of 24 patients J Am Acad Dermatol. 2017, 77:247-255. 10.1016/j.jaad.2017.02.021

9. Primka EJ 3rd, Camisa C: Methotrexate-induced toxic epidermal necrolysis in a patient with psoriasis . J Am Acad Dermatol. 1997, 36:815-818. 10.1016/s0190-9622(97)70029-х

10. Widemann BC, Adamson PC: Understanding and managing methotrexate nephrotoxicity. Oncologist. 2006, 11:694-703. 10.1634/theoncologist.11-6-694

11. Kremer JM, Alarcón GS, Weinblatt ME, et al.: Clinical, laboratory, radiographic, and histopathologic features of methotrexate-associated lung injury in patients with rheumatoid arthritis: a multicenter study with literature review. Arthritis Rheum. 1997, 40:1829-1837. 10.1002/art.1780401016

12. Bhojwani D, Sabin ND, Pei D, et al.: Methotrexate-induced neurotoxicity and leukoencephalopathy in childhood acute lymphoblastic leukemia. J Clin Oncol. 2014, 32:949-959. 10.1200/JCO.2013.53.0808

13. Gonzalez-Ibarra F, Eivaz-Mohammadi S, Surapaneni S, et al.: Methotrexate induced pancytopenia. Case Rep Rheumatol. 2014, 2014:679580. 10.1155/2014/679580

14. Amissah-Arthur MB, Baah W: Methotrexate-induced pancytopenia and mucositis caused by medication error. Ghana Med J. 2020, 54:68-71.

15. Cuthbert RJ, Craig JI, Ludlam CA: Stevens-Johnson syndrome associated with methotrexate treatment for 


\section{Cureus}

non-Hodgkin's lymphoma. Ulster Med J. 1993, 62:95-97.

16. Lawrence CM, Dahl MG: Two patterns of skin ulceration induced by methotrexate in patients with psoriasis . J Am Acad Dermatol. 1984, 11:1059-1065. 10.1016/s0190-9622(84)70259-3

17. Kazlow DW, Federgrun D, Kurtin S, Lebwohl MG: Cutaneous ulceration caused by methotrexate. J Am Acad Dermatol. 2003, 49:197-198. 10.1067/mjd.2003.388 